Ginat Paper

\title{
A New Model to Perform Electrophysiological Studies in the Early Embryonic Mouse Heart
}

\author{
Anna Kornblum ${ }^{a}$ Frank Pillekamp ${ }^{b}$ Matthias Matzkies ${ }^{a}$ Bernd Fleischmann ${ }^{c}$ \\ Hendrik Bonnemeierd Heribert Schunkert ${ }^{d}$ Konrad Brockmeier ${ }^{b}$ Jürgen Heschelera \\ Michael Reppel ${ }^{a, d}$ \\ aInstitute of Neurophysiology, University of Cologne, Cologne, Germany; ${ }^{b}$ Pediatric Cardiology, \\ University of Cologne, Cologne, Germany; Institute of Physiology I, Life \& Brain Center, University of \\ Bonn, Bonn, Germany; 'Medizinische Klinik II, Medical University of Lübeck, Lübeck, Germany
}

\section{Key Words}

Electrophysiology $\bullet$ Heart block $・$ Imaging $\bullet$ Atrioventricular node $\bullet$ Conduction

\begin{abstract}
Background: The first electrocardiograms (ECGs) have been recorded with a capillary electrometer in the late $19^{\text {th }}$ century by John Burdon Sanderson and Augustus Waller. In 1903 Willem Einthoven used the much more sensitive string galvanometer and was awarded Nobel Price in Medicine for this discovery. Though the physical principles of that era are still in use, there have been many advances but also challenges in cardiac electrophysiology over the last decades. One challenge is to record electrocardiograms of rather small animals such as mice and even smaller organisms such as their embryos. As mice belong to the most routinely used laboratory animals it is important to better understand their physiology and specific diseases. We therefore aimed to study whether it is feasible to measure electrical activities of embryonic mouse hearts. Methods and Results: For our studies we used substrate-integrated Microelectrode Arrays combined with newly developed stimulation electrodes to perform electrophysiological studies in these hearts. The system enabled us to perform ECG-like recordings with atrio-ventricular (anterograde) and ventriculo-atrial (retrograde) stimulation. The functional separation of atria and ventricles, indicated by a stable atrio-ventricular conduction time, occurred clearly earlier than the morphological separation. Electrical stimulation induced a reversible prolongation of the anterograde and retrograde conduction up to atrio-ventricular conduction blocks at higher frequencies. Conclusion: These results yield new insight into functional aspects of murine cardiac development, and may help as a new diagnostic tool to uncover the functional and electrophysiological background of embryonic cardiac phenotypes of genetically altered mice.
\end{abstract}


Kornblum et al.: ECG of the Embryonic Mouse Heart

\section{Introduction}

Rhythmical beating of the adult heart is based on coordinated electrical waves initiated and conducted by specialized cells of the cardiac conduction system. Electrical activity arises spontaneously in the sinoatrial node, is conducted through the atrial tissue and then reaches the ventricular working myocardium via a specialized atrioventricular (AV)conduction system.

Arrhythmogenesis and alterations of the physiological initiation and conduction of electrical signals are believed to originate in the very early stages of embryonic cardiogenesis [1]. Previous studies demonstrated that anatomical alterations in the developing cardiac conduction system can result in life-threatening arrhythmias [2]. However, largely due to technical limitations little is known about embryonic cardiac physiology. This study presents a new methodology to circumvent these challenges.

Microelectrode Arrays (MEAs) were originally developed for electrophysiologcial studies in brain slices but enabled us also to study extracellular electrical activity of cardiac tissue with high temporal and spatial resolution. Recent studies from our group demonstrated its feasibility for studying electrophysiology in human and rhesus monkey embryonic stem cell-derived cardiac clusters [3-5]. Measurement of extracellularly recorded field potentials (FPs), that similarly to the ECG result from the sum of electrical signals of all cells in the surrounding of the specific MEA electrode, hereby especially provides detailed information about the origin and spread of excitation in heart tissue. Additionally, the system measures the speed of the excitation spread and detects arrhythmias $[6,7]$. Consequently, the MEA system forms a subtle experimental methodology to study the electrophysiology of embryonic whole mount hearts.

In the developmental process heart formation starts with the design of a primary heart tube, which is separated into the inflow-tract, the AV-channel and the outflow-tract. As described by Moorman et al. this heart tube works like a peristaltic pump, slowly pressing the blood from one end of the heart tube to the other [8]. Around developmental day E10.5 atrial and ventricular chambers develop within this tube. These chambers consist of fast conducting myocardium and contract simultaneously. Connected with the morphological development is the maturation of the cardiac conduction system. First signs of this system, that derives from the embryonic working myocardium through largely unidentified mechanisms [9], can be detected at E8.5. By E9.5 precursors of the sinusnode, the AV-node and the ventricular conduction system can be morphologically visualized [10]. It is assumed, that the AV-node is formed by a subpopulation of primary myocardium from the atrioventricular-channel that is inhibited from further maturation into working myocardium $[8,11,12]$.

The present study aimed at studying whether it is feasible to measure electrical activities of embryonic mouse hearts and to functionally characterize the developing cardiac conduction system. To our knowledge this is the first study about ECG-like recordings of embryonic mouse hearts. We used hearts of two distinct developmental stages: tubular-like VEDS hearts (very early developmental stage, E8.5) and four-chambered EDS hearts (early developmental stage E10.5-E11.0).

Our results show, that in clear contrast to the morphological separation of atria and ventricles, that occurs around E10.5, functional separation was visible around E9.0 by emerging atrial and ventricular FPs with a distinctive ECG-like FP morphology and a fixed AV-conduction time. Moreover, electrical pacing -performed for analysis of the electrophysiological conduction properties- induced significant and reversible prolongation of $\mathrm{AV}$ - and VA-conduction at higher stimulation frequencies and led to frequency-dependent AV-blocks known to occur in humans. 
Fig. 1. System components and experimental setup. A) MEA system consisting of the heating device, amplifier and PC for storage and online as well as post processing of data (upper panel) and the substrate integrated microelectrode array (MEA, lower left panel) with $60 \mathrm{TiNi}$ coated electrodes (30 $\mu \mathrm{m}$ diameter, lower middle panel) arranged in an electrode grid with an interelectrode distance of $200 \mu \mathrm{m}$. The MEAs are integrated in the amplifier that is placed on an inverse microscope. A video camera is used for online visualization of heart contractions. B) Three different developmental stages of embryonic hearts plated on MEAs. C) Electrode used for external electrical pacing. D) Pacing protocol (upper panel) with original tracings (lower panel). E) Representative ECG-like recording of an EDS heart and nomenclature. F) Original tracing (1) before acute atrial stimulation, (2) during stimulation with $3 \mathrm{~Hz}$ and (3) after stimulation. Note the small pacing artefact and the prolongation of AV conduction during electrical pacing. Stimulation induced approximately $30 \%$ prolongation of AV conduction. The changes of ECG morphology during pacing completely recovered after stop of stimulation.

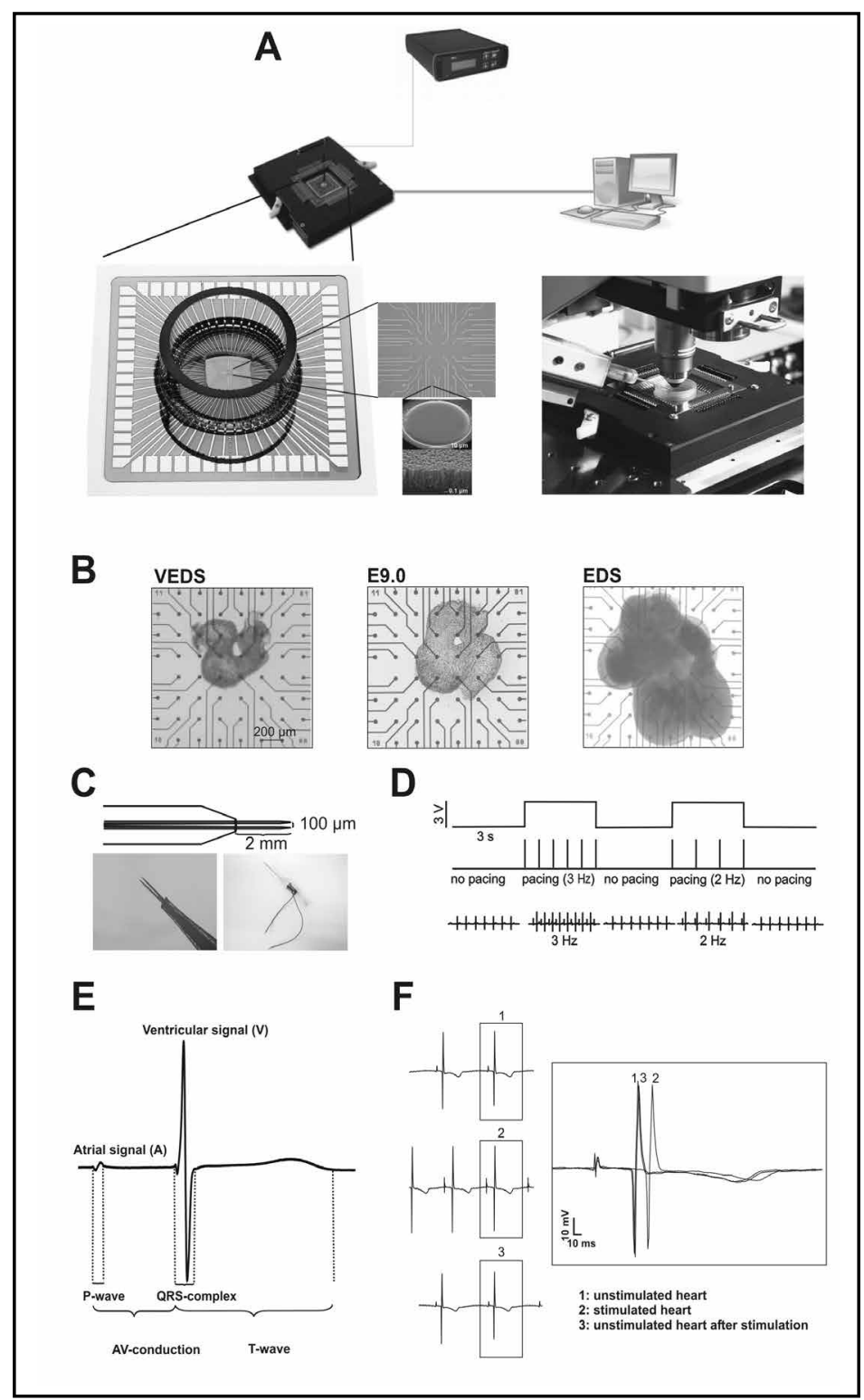

\section{Materials and Methods}

\section{Embryonic heart preparation}

Murine embryonic hearts were obtained from superovulated mice of the HIM:OF1 strain as described [13-15]. Very early (embryonic day E8.5, VEDS) and early (E10.0- E11.0, EDS) developmental stage embryonic whole mount mouse hearts were studied. At VEDS the hearts have a tubular tubular-like morphology whereas at EDS four-chambered hearts were observed (Fig. 1B).

FP recordings using MEAs

After plating and attachment of spontaneously beating embryonic hearts on MEAs, extracellular recording was performed using the MEA data acquisition system (Multi Channel Systems, Reutlingen, Germany, Fig. 1A). A standard MEA culture dish contains 60 titanium nitride-coated gold electrodes $(30 \mu \mathrm{m}$ diameter) arranged in an 8x8 electrode grid with an inter-electrode distance of $200 \mu \mathrm{m}$. The signal recorded with one of the extracellular electrodes reflects local changes of the membrane potential. Also currents such as voltage-dependent currents and passive capacitive currents that are generated by electrically connected neighboring tissue contribute to the FP morphology $[16,17]$. The amplifier system allows to simultane- 


\begin{tabular}{lcccc}
\hline \multicolumn{1}{c}{$\mathrm{n}=5$} & Unstimulated & Stimulated & Unstimulated & $\mathrm{P}$ \\
\hline Frequency (Hz) & $2.2 \pm 0.1$ & 3.0 & $2.0 \pm 0.2$ & 0.16 \\
P-wave (ms) & $8.5 \pm 1.8$ & $9.7 \pm 1.8$ & $9.8 \pm 1.3$ & 0.16 \\
AV-conduction & $79.5 \pm 22.2$ & $87.8 \pm 17.8$ & $70 \pm 12.2$ & 0.5 \\
QRS complex & $11.7 \pm 1.5$ & $13.4 \pm 1.9$ & $12.6 \pm 1.2$ & 0.09 \\
T-wave (ms) & $143.9 \pm 25.9$ & $133.5 \pm 7.0$ & $124.7 \pm 10$ & 0.53 \\
\hline
\end{tabular}

Table 1. ECG parameters of EDS hearts before, during, and after external electrical pacing of the atria. Note the prolongation of AV-conduction during stimulation with self-recovery post stimulation. Data are displayed as means \pm sem.

ously recording FPs from all electrodes at a sampling rate of 1 to $50 \mathrm{kHz}$. Standard measurements were performed at $5 \mathrm{kHz}$ (bandwidth 1-5 kHz) in standard Tyrode's solution. The extracellular solution contained (in mmol/L): $135 \mathrm{NaCl}, 5.4 \mathrm{KCl}, 2 \mathrm{CaCl}$, $1 \mathrm{MgCl} 2,10 \mathrm{HEPES}, 10$ glucose, adjusted to $\mathrm{pH} 7.4(\mathrm{NaOH})$. During recordings, temperature was kept at $37.0^{\circ} \mathrm{C}$. Data were analyzed off-line with a customized toolbox programmed with MATLAB (Mathworks, Natick, Mass, USA) [18]. In line with the observation of spontaneous and regular beating, FPs were found to be regular and similar in shape (Fig. 2).

All electrodes of the MEA culture dish can in principle be used for recording and electrical stimulation. Nevertheless, since stimulation requires optimal contact between electrode and tissue, we decided to apply external stimulation algorithms that can easily be applied via movable stimulation electrodes and the external stimulator.

\section{Electrical Pacing}

Embryonic hearts were tested for effects of electrical excitation applying acute external electrical pulses via custom made stimulation electrodes that were produced from two epoxy casting resin-coated V2a leads (1.4 301; diameter $40 \mu \mathrm{m}$ ) with an inter-lead distance of approximately 50-100 $\mu \mathrm{m}$ (Fig. 1C). No long-term measurements of effects of electrical stimulation itself on cardiac development were performed. Stimulation electrodes were connected to a square wave physiological stimulator (SD9, Grass Instrument Co., Quincy, MA) and placed on the heart using a Narashigi micromanipulator under microscopical control. For standard recordings untriggered ECGs were documented first. Afterwards anterograde and retrograde stimulation was performed placing the pacing electrode on the right atrium and left ventricle, respectively. The pacing frequency was set $10 \%$ above the untriggered heart rate to determine pacing thresholds that were analyzed in $0.5 \mathrm{~V}$ steps. For continuous recordings voltages $50 \%$ above threshold were used and the stimulator was adjusted to pulse duration of $10 \mathrm{~ms}$ and a slow frequency pattern of $0.5 \mathrm{~Hz}$ above the untriggered heart rate. According to the protocol shown in Fig. 1D pacing was performed for 30 sec intervals followed by untriggered intervals of identical length taken as control. The bipolar stimulation electrode resulted in recordings with low artificial signals (Fig. 1F).

\section{ECG parameters}

Due to the typical ECG-like shape of MEA recordings (Fig. 1E) we defined the following parameters: $P$-wave: Excitation of the atria, first small FP component at EDS. QRS complex: Excitation of the ventricle, first FP component at VEDS and second FP component at EDS. It includes the time from beginning to the end of the respective FP component. $A V$ conduction time: Time from the beginning of the atrial excitation (first FP) to the beginning of ventricular excitation (second FP). VA conduction time: Time from excitation of the ventricle to the beginning of the atrial excitation under ventricular pacing. It includes the time from the beginning of the first (ventricular) to the beginning of the second (atrial) FP component. T-wave: Indicates the repolarization of the ventricles. In contrast to adult murine hearts embryonic hearts showed a typical repolarization phase, i.e. a T wave-like FP component. The T-wave includes the time between the end of the first FP (at VEDS) or the second FP (at EDS) to the end of the T wave.

\section{Statistical Analysis}

Data are presented as mean \pm sem. For statistical analysis one or two tailed student's t-test were used where applicable. Statistical significance was set at $\mathrm{p}<0.05$. 


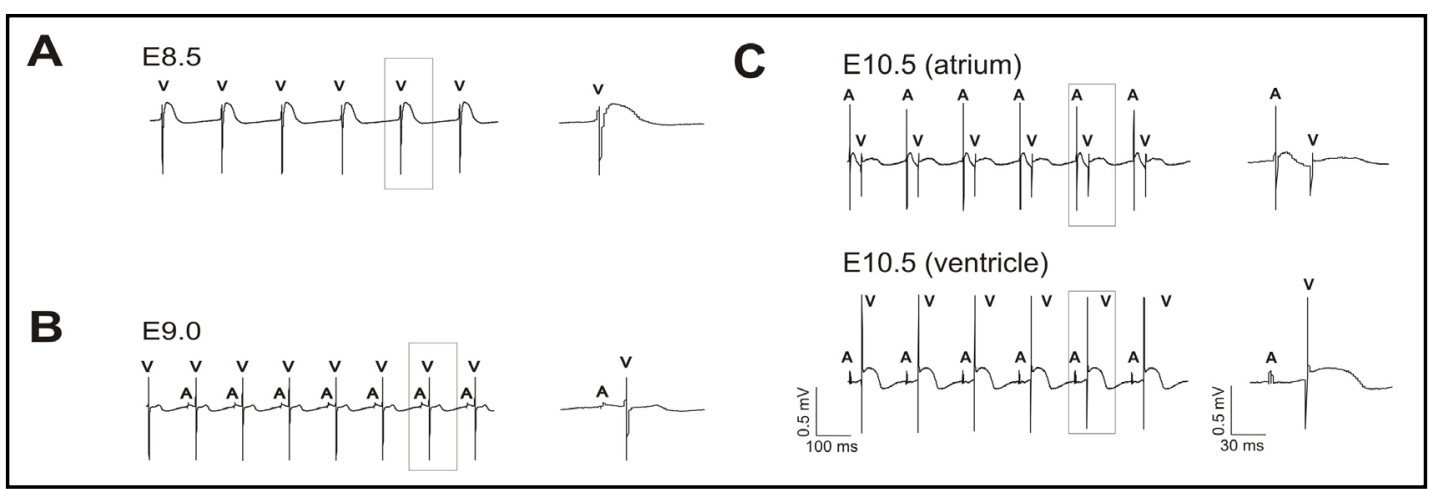

Fig. 2. Original traces of hearts that were not electrically stimulated. Representative ECGs derived from an E8.5 heart (A), E9.0 heart (B) and E10.5 heart (C). In (C) the upper panel was derived from an electrode that was covered by atrial tissue and the lower panel from an electrode that was covered with ventricular tissue. $(\mathrm{A}=$ atrial signal, $\mathrm{V}=$ ventricular signal). Note that $\mathrm{AV}$ conduction was prolonged by almost $50 \%$ in $\mathrm{E} 10.5$ as compared to E9.0 hearts.

Table 2. ECG parameters of E8.5 as compared to E10.5 hearts. There was only one potential detected in E8.5 hearts. QRS was significant shorter and $\mathrm{T}$ wave significantly prolonged in E10.5. Data are displayed as means \pm sem.

\begin{tabular}{lccc}
\hline & E8.5 $(\mathrm{n}=10)$ & $\mathrm{E} 10.5(\mathrm{n}=19)$ & $\mathrm{P}$ \\
\hline Frequency $(\mathrm{Hz})$ & $2.3 \pm 0.2$ & $2.3 \pm 0.1$ & 0.72 \\
& {$[1.7-3]$} & {$[1.3 \pm 3.7]$} & \\
P-wave (ms) & - & $7.7 \pm 0.4$ & - \\
& & {$[4.9-11.7]$} & \\
AV-conduction & - & $84.8 \pm 8.6$ & - \\
& & {$[28.8-158.2]$} & \\
QRS complex & $14.5 \pm 1.9$ & $9.4 \pm 0.6$ & $\mathbf{0 . 0 0 4}$ \\
& {$[8.5-22.1]$} & {$[5-15.2]$} & \\
T-wave (ms) & $83.3 \pm 3.8$ & $131 \pm 6.1$ & $<\mathbf{0 . 0 0 1}$ \\
& {$[66.4-104.1]$} & {$[98-199]$} & \\
\hline
\end{tabular}

\section{Results}

The murine embryonic ECG

For our studies on the evolution of the murine embryonic ECG we used hearts of two distinct developmental stages: tubular-like VEDS (embryonic day E8.5) hearts with a size of $0.75 \pm 0.02 \mathrm{~mm}(\mathrm{n}=10)$ as well as four-chambered EDS hearts (E10.5- E11.0), which were with $1.4 \pm 0.03 \mathrm{~mm}(\mathrm{n}=19)$ significantly larger. After preparation the hearts attached to the MEA culture dishes that were integrated into the MEA system (Fig. 1) and allowed stable recordings of spontaneous electrical activity 2-4 hours later.

Microscopical inspection revealed slow coordinated peristaltic contraction waves at VEDS with a rhythmical beating frequency of $2.3 \pm 0.2 \mathrm{~Hz}(\mathrm{n}=10)$. At EDS fast atrial triggered contractions of the ventricles could be detected with a frequency of $2.2 \pm 0.1 \mathrm{~ms}(\mathrm{n}=19$; $\mathrm{p}>0.05$ ). When paralleled by electrical signals recorded with the MEA system basal heart rates were $2.3 \pm 0.2 \mathrm{~Hz}$ at VEDS $(n=10)$ and $2.3 \pm 0.1 \mathrm{~Hz}$ at EDS $(n=19, p>0.05)$ indicating that each electrical signal led to a mechanical contraction.

MEA recordings at VEDS only showed one single, QRS-complex-like, FP spike every heartbeat (Fig. 2A) whereas at EDS the recorded FPs displayed two different spikes, one P-wave-like and one QRS-complex-like, with an apparent delay of $84.8 \pm 8.6 \mathrm{~ms}$ (Fig. 1B, C, Table 2). The P-wave-like spike showed the highest amplitude at electrodes covered with atrial tissue whereas the QRS-like-spike had highest amplitudes at electrodes covered with ventricular tissue (Fig. 2C). During the developmental process of embryonic hearts the first sign of a P-wave-like signal could be detected from the developmental stage E9.0 on, when the heart still looks like a tube (Fig. 2). 


\section{Cellular Physiology and Biochemistry}

Cell Physiol Biochem 2013;32:1-10

\begin{tabular}{l|l}
\hline DOI: $10.1159 / 000350118$ & C 2013 S. Karger AG, Basel
\end{tabular}

Publisned oniIne: July 04, 2013 www.karger.com/cpb

Kornblum et al.: ECG of the Embryonic Mouse Heart
Fig. 3. Original traces of hearts that were electrically stimulated. A) Representative recordings of hearts that were temporary paced at the atria (left panel). Note the prolongation of $\mathrm{AV}$-conduction at higher pacing frequencies leading to AV-conduction blocks as in humans (Wenckebach phenomenon, lower left panel). On the right hand side the range of stimulation frequencies that were accepted during pacing (upper panel) and the prolongation of the $\mathrm{AV}$-conduction with respect to the applied frequency (lower panel) are shown. B) Representative recordings of EDS hearts that were paced at the left ventricle with different frequencies (left panel) and the range of accepted stimulation frequencies (upper right panel) and the prolongation of the VAconduction at different frequencies (lower right panel). C) Original, electrically triggered traces recorded from the same heart. Note that the AV-conduction (upper panel) is significantly shorter as compared to the VA-conduction (lower panel).

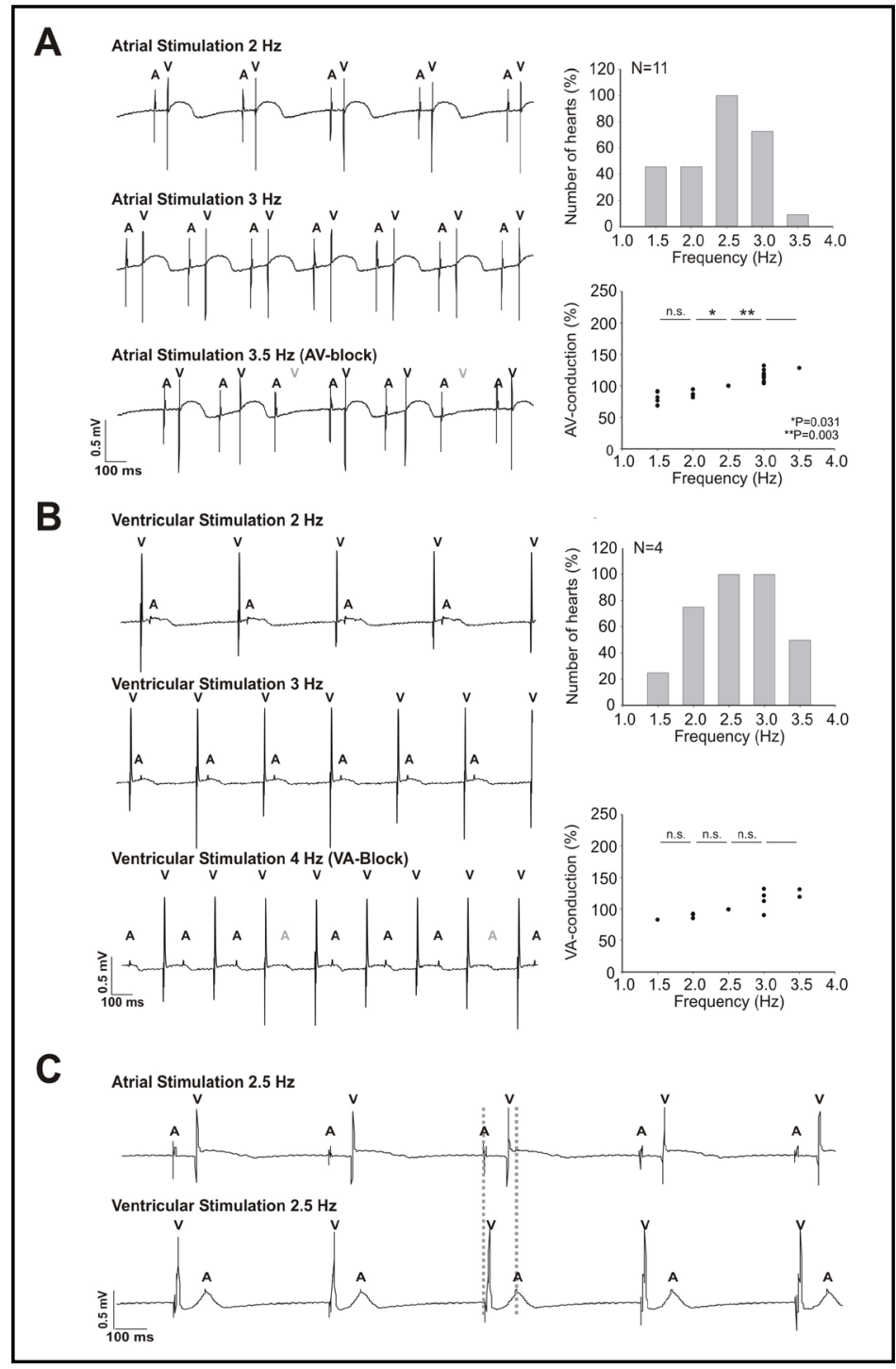

\begin{tabular}{lcccc}
\hline & $1.5 \mathrm{~Hz}(\mathrm{n}=5)$ & $2 \mathrm{~Hz}(\mathrm{n}=5)$ & $2.5 \mathrm{~Hz}(\mathrm{n}=11)$ & $3 \mathrm{~Hz}(\mathrm{n}=8)$ \\
\hline P-wave $(\mathrm{ms})$ & $7.2 \pm 0.7$ & $7.6 \pm 1.1$ & $8.1 \pm 0.9$ & $7.6 \pm 1.2$ \\
AV-conduction & $74.9 \pm 12.8$ & $85.2 \pm 11.1$ & $89.7 \pm 6.9$ & $101.2 \pm 9.5$ \\
QRS complex & $9.1 \pm 1.9$ & $9.1 \pm 1.5$ & $9.6 \pm 0.9$ & $10 \pm 1.7$ \\
T-wave (ms) & $153.4 \pm 16.5$ & $153.9 \pm 14.5$ & $146.8 \pm 7.3$ & $139.2 \pm 2.8$ \\
\hline
\end{tabular}

Table 3. ECG parameters during atrial stimulation of E10.5 hearts at different frequencies. Note the significant prolongation of the AV-conduction with rising stimulation frequencies. As in humans we found a frequency-dependent shortening of the T-wave. Data are displayed as means \pm sem.

\section{ECG parameters at VEDS and EDS}

Exact values of the calculated ECG-parameters (P-wave, AV-conduction, QRS-complex and T-wave) as well as the spontaneous beating frequencies of VEDS and EDS hearts are shown in Table 2. Since at VEDS only a single FP spike could be detected, P-wave and AVconduction were only analyzed for EDS hearts. 


\begin{tabular}{lccc}
\hline & $2 \mathrm{~Hz}(\mathrm{n}=3)$ & $2.5 \mathrm{~Hz}(\mathrm{n}=4)$ & $3 \mathrm{~Hz}(\mathrm{n}=4)$ \\
\hline P-wave $(\mathrm{ms})$ & $8.3 \pm 1.7$ & $8.3 \pm 1.4$ & $7.4 \pm 0.9$ \\
VA-conduction & $70.1 \pm 0.9$ & $75.6 \pm 3$ & $87.2 \pm 8.6$ \\
QRS complex & $9.7 \pm 2.3$ & $10.1 \pm 2$ & $11.4 \pm 1.9$ \\
T-wave $(\mathrm{ms})$ & $179.2 \pm 20.7$ & $155 \pm 23.1$ & $150.8 \pm 22.5$ \\
\hline
\end{tabular}

Table 4. ECG parameters during ventricular stimulation of E10.5 hearts at different frequencies. Also with retrograde stimulation VA-conduction prolonged with rising stimulation frequencies. Data are displayed as means \pm sem.

\begin{tabular}{lccc}
\hline \multicolumn{1}{c}{$\mathrm{n}=3$} & $\begin{array}{c}2.5 \mathrm{~Hz} \\
\text { retrograde }\end{array}$ & $\begin{array}{c}2.5 \mathrm{~Hz} \\
\text { anterograde }\end{array}$ & $\mathrm{P}$ \\
\hline P-wave (ms) & $8.1 \pm 1.9$ & $9.2 \pm 2.5$ & 0.34 \\
VA-/AV-conduction & $73.1 \pm 2.3$ & $56.6 \pm 1.3$ & 0.043 \\
QRS complex & $10.7 \pm 2.7$ & $12.2 \pm 1.3$ & 0.45 \\
T-wave (ms) & $133.4 \pm 11.7$ & $137.9 \pm 21.5$ & 0.88 \\
\hline
\end{tabular}

Table 5. ECG parameters during anterograde versus retrograde stimulation of E10.5 hearts at $2.5 \mathrm{~Hz}$. Note the significant shorter AV-/VA-conduction with antegrade versus retrograde stimulation. Data are displayed as means \pm sem.

At VEDS neither the QRS-complex nor the T-wave length showed an apparent correlation with the spontaneous beating frequency. Likewise, at EDS, no correlation of the P-wave and the QRS width with heart rate were found. Also the AV-conduction-time of EDS-derived hearts did not correlate with the heart rate. However, the T-wave became shorter at higher spontaneous beating frequencies (correlation coefficient $=-0.74$ ).

Statistical comparison of the ECG-parameters showed a significantly prolonged QRS complex in VEDS hearts as compared to EDS hearts $(14.5 \pm 1.9 \mathrm{~ms}$ versus $9.4 \pm 0.6 \mathrm{~ms}$; $\mathrm{p}=0.004)$ and a significantly shorter T-wave for VEDS than for EDS hearts $(83.9 \pm 3.8 \mathrm{~ms}$ versus $131.0 \pm 6.1 \mathrm{~ms} ; \mathrm{p}<0.001$ ).

\section{Electrophysiological study of murine embryonic hearts}

For further investigation of the AV-conduction a special pacing procedure was established using novel midget-stimulation electrodes with an inter-lead distance of 50-100 $\mu \mathrm{m}$. This procedure allowed to determine standard ECG parameters under atrial or ventricular pacing and to search for pathophysiological findings, such as the Wenckebach phenomenon. As MEA measurements of VEDS hearts only showed one single spike that did not allow to measure the AV-conduction time, electrical pacing was only performed in EDS hearts. Atrial pacing with anterograde conduction to the ventricles (AV) as well as ventricular stimulation with retrograde (VA) conduction to the atria was performed (Fig. 3). Notably, atrial stimulation did not alter the QRS-complex and T-wave morphology indicating that only the trigger of the heart beat was changed and the main conduction pathway left unaffected (Fig. 1F). Moreover, although the AV-conduction was temporarily prolonged under stimulation, the ECG-parameters completely recovered to baseline when the stimulation ended (Fig. 1F, Table 1). The comparison of ECG-parameters during electrical pacing via right or left atrium did not show significant differences (data not shown). Hence, electrophysiological studies of the early murine embryonic heart are possible and safe. 
ECG parameters during atrial and ventricular stimulation

The range of stimulation frequencies that were accepted by most of the hearts (93.2\%) during atrial and ventricular pacing (Fig. 3) was $2.5-3 \mathrm{~Hz}$, no matter whether anterograde or retrograde stimulation was applied. In contrast, electrical pacing with frequencies of 3.5 $\mathrm{Hz}$ and above was only accepted sporadically (29.6 \%). Tables 3 and 4 show the statistical analysis of the ECG parameters during anterograde and retrograde stimulation. The striking observation was that anterograde stimulation with increasing stimulation frequencies evoked a distinct prolongation of the AV-conduction time (Table 3, Fig. 3). The escalation of the frequency from $1.5 \mathrm{~Hz}$ to $2 \mathrm{~Hz}$ did not reveal a significant change $(74.9 \pm 12.8 \mathrm{~ms}$ versus $85.2 \pm 11.1 \mathrm{~ms} ; \mathrm{p}=0.062$ ) but a change from to $2.5 \mathrm{~Hz}$ and $3 \mathrm{~Hz}$ led to a significant prolongation of the AV-conduction time to $89.7 \pm 6.9 \mathrm{~ms}(\mathrm{p}=0.031)$ and $101.2 \pm 9.5 \mathrm{~ms}(\mathrm{p}=0.003)$, respectively. As consequence pacing frequencies of $3 \mathrm{~Hz}$ and above were only accepted rarely and led to the Wenckebach phenomenon (Fig. 3A).

When during retrograde stimulation heart rate was increased from $2 \mathrm{~Hz}$ to $2.5 \mathrm{~Hz}$ and to $3 \mathrm{~Hz}$ a distinct prolongation of the VA-conduction time from $70.1 \pm 0.9 \mathrm{~ms}$ at $2 \mathrm{~Hz}$ to $75.6 \pm 3.0$ at $2.5 \mathrm{~Hz}$ and to $87.2 \pm 8.6 \mathrm{~ms}$ at $3 \mathrm{~Hz}$ was observed. Specialization of the AV-conduction pathway was indicated by significant faster $\mathrm{AV}$ than VA conduction at $2.5 \mathrm{~Hz}(56.6 \pm 1.3 \mathrm{~ms}$ versus $73.1 \pm 2.3 \mathrm{~ms} ; \mathrm{p}=0.043$ ) (Fig. $3 \mathrm{C}$ and Table 5 ). By contrast, the $\mathrm{T}$-wave showed a trend to become shorter at higher anterograde and retrograde pacing frequencies (Table 3,4). The P-wave and the QRS-complex did not undergo remarkable changes during the stimulation procedure, neither during atrial nor ventricular pacing.

\section{Discussion}

In the present paper we performed electrophysiological studies in early murine embryonic hearts. Using the high-resolution MEA system, we studied spontaneous and electrically triggered heart activity. We observed (i) monophasic ECG-like recordings already at VEDS, presence of a P-wave, AV- and VA-conduction, QRS complex and a T-wave at EDS, (ii) occurrence of atrial P-wave-like signals prior to morphological separation of atria and ventricles, (iii) significant prolongation of the AV-conduction at higher pacing frequencies and (iv) typical AV-conduction blocks such as the Wenckebach penomenon.

At E8.0 a peristaltic blood flow and high blood viscosity allow coordinated blood flow despite the lack of heart valves and chambers $[8,19]$. Our most surprising finding was, that although it is generally accepted that atria and ventricles separate morphologically around day E10.5 in mice, we observed electrical separation already at day E9.0. In line with studies about the development of the ECG in chick embryos our studies showed that the development of the adult-like ECG with a P-wave and QRS-complex emerges from a single field potential [20]. In morphological studies [21] and through analysis of lacZ expression in transgenic mice [22] first specialized cells of the AV-conduction pathway could be visualized around E8.5-E9.5 in the AV-channel that connects atria and ventricles of the developing heart. Our results show, that these specialized cells are already functionally active and delay the AV-conduction even at very early stages of cardiac conduction system development probably due to a lower level of gap junctions [23]. From a physiological point of view the slow impulse propagation is crucial because the embryonic heart is not yet equipped with heart valves [19].

The newly developed electrophysiological study system allowed ECG-like recordings already at the earliest stages of cardiac development, VEDS, a stage at which the heart measures below $1 \mathrm{~mm}$. VEDS and EDS hearts established a stable beating over days in culture. In line with data from human hearts, we found all typical ECG parameters at EDS, i.e. P-wave and QRS complex with a distinct AV conduction time, and T-wave. Interestingly, we found a typical T-wave that is not known from adult mice [24]. Changes of ion channel expression, such as significant increase of $\mathrm{Na}^{+}$and $\mathrm{K}^{+}$channel density during heart development [25], as 
Kornblum et al.: ECG of the Embryonic Mouse Heart

an underlying reason for the increase of heart rate during murine cardiac development and the shortened repolarization phase in adult mice may serve as an explanation.

We found that embryonic hearts responded to electrical stimulation in a narrow frequency range. The accepted frequency spectrum was significantly lower than that known for adult mice that accept pacing up to $100-110 \mathrm{~Hz}$ [24]. A possible explanation is the immaturity of the hearts, e.g. immature equipment of the sarcolemma with ion channels [25] and of the contractile apparatus [26].

Established stimulation protocols are essential for standardized electrophysiological studies. This became obvious when we compared ECG parameters at spontaneous beating rates with their corresponding values at triggered frequencies. When the atria were stimulated, AV-conduction was first slowly prolonging then remained at stable levels and finally returned to basal values after pacing was stopped. The AV- and VA-conduction time became slower during electrical pacing with triggered frequencies above basal heart rate. The higher the triggered frequency was, the slower the AV-conduction became finally leading to the Wenckebach phenomenon. This might resemble a protective mechanism, which has previously been described in adult hearts as 'cycle length dependent delay' [27, 28]. Some of the cells of the AV-node, called N-cells, do not respond to excitation at higher frequencies due to a prolonged repolarization. The above mentioned phenomena limit AV-conduction to ensure anterograde transport of the highly viscous blood. This hypothesis is supported by immuncytochemical findings in embryonic mouse hearts where an increase of gap junctions during maturation has been reported [8]. In summary our results may help to better understand function of the developing heart.

\section{References}

1 Janse MK, Anderson RH, van Capelle FJ, Durrer D: A combined electrophysiological and anatomical study of the human fetal heart. Am Heart J 1976;91:556-562.

-2 Jongbloed MR, Schalij MJ, Poelmann RE, Blom NA, Fekkes ML, Wang Z, Fishman GI, Gittenberger-De Groot AC: Embryonic conduction tissue: a spatial correlation with adult arrhythmogenic areas. J Cardiovasc Electrophysiol 2004;15:349-355.

3 Reppel M, Pillekamp F, Lu ZJ, Halbach M, Brockmeier K, Fleischmann BK, Hescheler J: Microelectrode arrays: a new tool to measure embryonic heart activity. J Electrocardiol 2004; 37:S104-109.

-4 Reppel M, Pillekamp F, Brockmeier K, Matzkies M, Bekcioglu A, Lipke T, Nguemo F, Bonnemeier H, Hescheler J: The electrocardiogram of human embryonic stem cell-derived cardiomyocytes. J Electrocardiol 2005;38:166-170.

-5 Schwanke K, Wunderlich S, Reppel M, Winkler ME, Matzkies M, Groos S, Itskovitz-Eldor J, Simon AR, Hescheler J, Haverich A, Martin U: Generation and characterization of functional cardiomyocytes from rhesus monkey embryonic stem cells. Stem Cells 2006;24:1423-1432.

-6 Banach K, Halbach MD, Hu P, Hescheler J, Egert U: Development of electrical activity in cardiac myocyte aggregates derived from mouse embryonic stem cells. Am J Physiol Heart Circ Physiol 2003;284:H2114H2123.

7 Halbach M, Egert U, Hescheler J, Banach K: Estimation of action potential changes from field potential recordings in multicellular mouse cardiac myocyte cultures. Cell Physiol Biochem 2003;13:271-284.

-8 Moorman AF, de Jong F, Denyn MM, Lamers WH: Development of the cardiac conduction system. Circ Res 1998;82:629-644.

-9 Rentschler S, Zander J, Meyers K, France D, Levine R, Porter G, Rivkees SA, Morley GE, Fishman GI: Neuregulin-1 promotes formation of the murine cardiac conduction system. Proc Natl Acad Sci U S A 2002;99:10464-10469.

10 Rentschler S, Vaidya DM, Tamaddon H, Degenhardt K, Sassoon D, Morley GE, Jalife J, Fishman GI: Visualization and functional characterization of the developing murine cardiac conduction system. Development 2001;128:1785-1792. 
11 Yutzey KE: Teed off: cardiac conduction system development requires T-box transcription factors. Circ Res 2008;102:1295-1297.

12 Mikawa T, Hurtado R: Development of the cardiac conduction system. Semin Cell Dev Biol 2007;18:90-100.

13 Herr C, Smyth N, Ullrich S, Herr C, Smyth N, Ullrich S, Yun F, Sasse P, Hescheler J, Fleischmann B, Lasek K, Brixius K, Schwinger RH, Fässler R, Schröder R, Noegel AA: Loss of annexin A7 leads to alterations in frequency-induced shortening of isolated murine cardiomyocytes. Mol Cell Biol 2001;21:4119-4128.

14 Fleischmann M, Bloch W, Kolossov E, Andressen C, Müller M, Brem G, Hescheler J, Addicks K, Fleischmann BK: Cardiac specific expression of the green fluorescent protein during early murine embryonic development. FEBS Lett 1998;440:370-376.

-15 Reppel M, Sasse P, Piekorz R, Tang M, Roell W, Duan Y, Kletke A, Hescheler J, Nürnberg B, Fleischmann BK: S100A1 enhances the L-type $\mathrm{Ca}^{2+}$ current in embryonic mouse and neonatal rat ventricular cardiomyocytes. J Biol Chem 2005;280:36019-36028.

16 Banach K, Halbach MD, Hu P, Hescheler J, Egert U: Development of electrical activity in cardiac myocyte aggregates derived from mouse embryonic stem cells. Am J Physiol Heart Circ Physiol 2003;284:H2114H2123.

17 Hescheler J, Halbach M, Egert U, Lu ZJ, Bohlen H, Fleischmann BK, Reppel M: Determination of electrical properties of ES cell-derived cardiomyocytes using MEAs. J Electrocardiol 2004;37:S110-116.

18 Egert U, Knott T, Schwarz C, Nawrot M, Brandt A, Rotter S, Diesmann M: MEA-Tools: an open source toolbox for the analysis of multi-electrode data with MATLAB. J Neurosci Methods 2002;117:33-42.

19 Moorman AF, Christoffels VM: Cardiac chamber formation: development, genes, and evolution. Physiol Rev 2003;83:1223-1267.

20 Paff GH, Boucek RJ, Harrell TC: Observations on the development of the electrocardiogram. Anat Rec 1968;160:575-582.

21 Viragh S, Challice CE: The development of the conduction system in the mouse embryo heart. I. The first embryonic A-V conduction pathway. Dev Biol 1977;56:382-396.

22 Rentschler S, Vaidya DM, Tamaddon H, Degenhardt K, Sassoon D, Morley GE, Jalife J, Fishman GI: Visualization and functional characterization of the developing murine cardiac conduction system. Development 2001;128:1785-1792.

-23 Alcolea S, Theveniau-Ruissy M, Jarry-Guichard T, Marics I, Tzouanacou E, Chauvin JP, Briand JP, Moorman AF, Lamers WH, Gros DB: Downregulation of connexin 45 gene products during mouse heart development. Circ Res 1999;84:1365-1379.

-24 Liu G, Iden JB, Kovithavongs K, Gulamhusein R, Duff HJ, Kavanagh KM: In vivo temporal and spatial distribution of depolarization and repolarization and the illusive murine T wave. J Physiol 2004;555:267-279.

25 Davies MP, An RH, Doevendans P, Kubalak S, Chien KR, Kass RS: Developmental changes in ionic channel activity in the embryonic murine heart. Circ Res 1996;78:15-25.

-26 Haddad F, Qin AX, Bodell PW, Jiang W, Giger JM, Baldwin KM: Intergenic transcription and developmental regulation of cardiac myosin heavy chain genes. Am J Physiol Heart Circ Physiol 2008;294:H29-H40.

27 Amellal F, Hall K, Glass L, Billette J: Alternation of atrioventricular nodal conduction time during atrioventricular reentrant tachycardia: are dual pathways necessary? J Cardiovasc Electrophysiol 1996;7:943-951.

28 Meijler FL, Janse MJ: Morphology and electrophysiology of the mammalian atrioventricular node. Physiol Rev 1988;68:608-647. 